\title{
Global neurosurgery: models for international surgical education and collaboration at one university
}

\author{
Joao Paulo Almeida, MD, ${ }^{1}$ Carlos Velásquez, MD,,2 Claire Karekezi, MD, ${ }^{1}$ Miguel Marigil, MD, PhD, ${ }^{1}$ \\ Mojgan Hodaie, MD, PhD, ${ }^{1}$ James T. Rutka, MD, PhD, FRCSC, ${ }^{1}$ and \\ Mark Bernstein, MD, MHSc, FRCSC1
}

${ }^{1}$ Division of Neurosurgery, Toronto Western Hospital/University Health Network, University of Toronto, Ontario, Canada; and ${ }^{2}$ Hospital Universitario Marqués de Valdecilla and Fundación Instituto de Investigación Marqués de Valdecilla, Santander, Spain

OBJECTIVE International collaborations between high-income (HICs) and low- and middle-income countries (LMICs) have been developed as an attempt to reduce the inequalities in surgical care around the world. In this paper the authors review different models for international surgical education and describe projects developed by the Division of Neurosurgery at the University of Toronto in this field.

METHODS The authors conducted a review of models of international surgical education reported in the literature in the last 15 years. Previous publications on global neurosurgery reported by the Division of Neurosurgery at the University of Toronto were reviewed to exemplify the applications and challenges of international surgical collaborations.

RESULTS The most common models for international surgical education and collaboration include international surgical missions, long-term international partnerships, fellowship training models, and online surgical education. Development of such collaborations involves different challenges, including limited time availability, scarce funding/resources, sociocultural barriers, ethical challenges, and lack of organizational support. Of note, evaluation of outcomes of international surgical projects remains limited, and the development and application of assessment tools, such as the recently proposed Framework for the Assessment of International Surgical Success (FAIRNeSS), is encouraged.

CONCLUSIONS Actions to reduce inequality in surgical care should be implemented around the world. Different models can be used for bilateral exchange of knowledge and improvement of surgical care delivery in regions where there is poor access to surgical care. Implementation of global neurosurgery initiatives faces multiple limitations that can be ameliorated if systematic changes occur, such as the development of academic positions in global surgery, careful selection of participant centers, governmental and nongovernmental financial support, and routine application of outcome evaluation for international surgical collaborations.

https://thejns.org/doi/abs/10.3171/2018.7.FOCUS18291

KEYWORDS education; international; global; neurosurgery; collaboration

A CCESS to surgical care is disproportional around the world. According to current data, the population in the $30 \%$ of the lowest-income countries receive $3.5 \%$ of the worldwide surgical procedures each year, whereas the population in the $30 \%$ of the high-income countries (HICs) receive almost $75 \% .{ }^{35,38}$ An estimated 5 billion people do not have adequate access to surgical care, leading to significant social and economic impact. ${ }^{26,27}$

This inequality is even more striking in terms of neu- rosurgical care. ${ }^{8,29}$ While China and Japan have approximately 18,000 neurosurgeons, the African continent has only approximately 990 . To balance the current case deficit in neurosurgical care (5.2 million), it is estimated that an additional 22,626 neurosurgeons would be necessary. ${ }^{9}$ Aside from the shortage of qualified surgeons, the infrastructure for surgical care in many low- and middleincome countries (LMICs) is limited and impacts the delivery of adequate care.

ABBREVIATIONS FAIRNeSS $=$ Framework for the Assessment of International Surgical Success; $H I C=$ high-income country; LMIC = low- and middle-income country; NED = Neurosurgery, Education and Development. 
The concept of global surgery has been developed with the aim to minimize such inequality and promote academic and clinical collaborations between HICs and LMICs (Table 1). Multiple neurosurgical collaborations have been developed between HIC and LMIC institutions in the last 15 years. ${ }^{4,5,9,17,20,22,24,25,30-32,34,36}$ Although the establishment of initiatives such as the Foundation for International Education in Neurological Surgery (FIENS) ${ }^{3}$ and the Neurosurgery, Education and Development (NED) Foundation have supported this cause, most projects are still being organized by individual or single-center initiatives, and face financial, organizational, and academic challenges.

In the current project, we aim to discuss the different models for international surgical education and the challenges associated with the development of international collaborations. The experience of our Division of Neurosurgery (Toronto) is used to illustrate those models.

\section{Methods}

We reviewed the initiatives in international education developed by the Division of Neurosurgery of the University of Toronto in the past 15 years involving collaborations with LMICs. The initiatives were classified as 1) local-based structured training programs; 2) neurosurgical education missions overseas; 3) online surgical curriculums; and 4) long-term personal mentorships. The experiences from each model are summarized in this paper.

\section{Results}

\section{Local-Based Structured Training Programs}

In the local-based structured training program model, a visiting neurosurgeon from an LMIC temporarily joins an academic training program in an HIC. These programs include short- or long-term fellowship programs. An example of this model is the Neuro-oncology and Skull Base Surgery Fellowship of the University of Toronto at the Toronto Western Hospital. This is a 1-year training program $^{22}$ that exposes trainees to a wide range of procedures for intraaxial and skull base tumors. Since 2010, 27 neurosurgeons from different countries have been trained in the program and, among them, 6 came from an LMIC (2 trainees from Egypt and 1 each from Nigeria, India, Ethiopia, and Rwanda). The funding for the LMIC fellows was specifically allocated through the Greg Wilkins-Barrick Chair, since it was first established in 2011.

This program entails numerous advantages for neu- rosurgeons coming from LMICs. It allows training in a high-volume neurosurgical center and gives fellows the opportunity to be immersed in a comprehensive academic program at the University of Toronto. They have the opportunity to exchange experiences with neurosurgeons from around the world and to build long-term collaborations. Finally, fellows have the opportunity to participate in clinical research projects. This is an important part of training, useful for development of a critical methodological-based approach to investigate questions in neurooncology.

A similar training program has been developed at the Hospital for Sick Children through the Prakash Foundation Low Income Country Surgical Scholarships, where surgeons from low-income countries can apply for fellowship training in pediatric neurosurgery at the University of Toronto. Despite the significant and obvious advantages of this postgraduate training program, some challenges arise. Fellows from LMICs may find major difficulties when trying to introduce the techniques learned during training in her or his country of origin. Such procedures usually require technological resources, which may not be available upon returning home.

\section{Neurosurgical Education Missions}

Neurosurgical education missions are probably the most common model of international surgical collaboration. They are based on organized, often multidisciplinary trips to LMICs with a philanthropic goal in healthcare. The objectives of the missions can include healthcare assistance, surgical training, clinical research assistance, and a combination of all of them.

In our Division, missions have been organized by neurooncology (Mark Bernstein), pediatric (James Rutka), and functional (Mojgan Hodaie) neurosurgeons. A total of 25 missions were performed in 8 LMICs from 2008 to 2018. The main objectives, the host institutions, and the number of members of the missions, among other features, are specified in Table 2 . The rate of missions per year was about 3 , which has remained stable over the years, and the average duration was $10-12$ days with a range of 5-16 days. Several local neurosurgeons, neurosurgery residents, nurses, anesthetists, and researchers participated in the activities during each mission. The number of patients treated was approximately 8 on average per mission. A total of 5 pediatric neurosurgery educational missions to Ukraine were organized in recent years, helping the development of pediatric neurosurgical care in that country through

TABLE 1. Highlights of global surgery programs

\begin{tabular}{l}
\hline Summary of the Main Points Applied in Global Neurosurgery \\
\hline Solid long-term partnership btwn mentor, international trainee, \& host country \\
\hline Adequate institutional relationships btwn the HIC \& LMIC involved in the project \\
\hline Strategic plan defined before the visit w/ clearly defined outcomes \& expected challenges \\
\hline Awareness \& foresight of the individual, cultural, \& systemic limitations in the host country \\
\hline Action plan necessary to develop the intended surgical \& educational goals \\
\hline Measure of the input-output flow through specific surgical criteria (FAIRNeSS) \\
\hline Establishment of centers of excellence in global neurosurgery w/in HIC-affiliated academic hospitals
\end{tabular}


TABLE 2. Summary of the relationships for host countries and missions/participants involved (2010-2018)

\begin{tabular}{lcccccccccc}
\hline \multirow{2}{*}{ Variable } & \multicolumn{6}{c}{ Host Country Receiving the Program } \\
\cline { 2 - 9 } & Indonesia & Ethiopia & Kenya & Zambia & Nigeria & Ukraine & Cambodia & Ghana \\
\hline No. of missions & 1 & 3 & 6 & 1 & 4 & 5 & 1 & 4 \\
\hline Visiting neurosurgeon from University of Toronto & Bernstein & Bernstein & Bernstein & Bernstein & Bernstein & Rutka & Hodaie & Hodaie \& Bernstein \\
\hline Creation of long-term mentorship program & Yes & Yes & Yes & No & Yes & Yes & Yes & Yes \\
\hline
\end{tabular}

an exchange of information and surgical skills between healthcare professionals. ${ }^{32}$

The structure of each mission is divided into three phases: 1) planning and preparation before the mission; 2) the mission proper; and 3) the postmission follow-up and impact assessment. The first phase consists of definition of goals and operational planning; the mission itself generally includes surgical activities and lectures for dissemination of knowledge; the third phase mainly consists of evaluation of results and planning of long-term collaborations.

The educational objectives are planned in a format to address problems that require further training at the host institution. Additionally, training is designed to maximize the chances of long-term sustainability in the local health system and to minimize dependency on HIC institutions. Most international missions were focused on improving the surgical care of neurooncology patients, including education about pre- and postoperative assessment and awake craniotomy techniques. The funding was allocated through the Greg Wilkins-Barrick Chair for the neurooncology missions and the Prakash Foundation for the pediatric neurosurgery missions.

\section{Online Surgical Curriculum}

The widespread use of the Internet has revolutionized education. Distance electronic learning (eLearning) has become an accepted teaching tool, widely used in the field of medicine. ${ }^{25}$ Different organizations such as the Ptolemy Project (Canada) have developed eLearning platforms with the goal of supplementing the surgical training of physicians from LMICs. One of the major advantages of online models is their low cost and good educational results. An online model is a potential substitute to the surgical mission model in selected cases, which is also highly effective but significantly more expensive. While it is estimated that more than $\$ 250$ million is spent each year for surgical trips alone, ${ }^{25,31,32}$ eLearning projects would demand a fraction of this cost. Additionally, this model allows the students/trainees to have access to the learning material on demand, so review of different topics can be conducted at virtually any time and at any location.

The advantages of this model include the possibility of maintaining long-term contact with centers of interest in LMICs and creating an ongoing and consistent educational experience. Therefore, this model is useful for periods between missions when a lack of contact can undermine the development of the project. ${ }^{3}$ This model also integrates well within virtually any established surgical training program and complements the training that residents receive locally.

Our Division has developed an online platform with structured neurosurgical courses. ${ }^{3}$ In this initiative, the online courses have the advantage of simulating a faceto-face classroom, with defined faculty and trainees, a set duration, and a defined curriculum. Before course implementation, the appropriate software platform needs to be chosen and the needs of the target population must be considered.

Among the limitations encountered, the lack of technological resources, such as Internet access, can affect the success of the model. Fortunately, the absence of the Internet is now rare in almost any given country. Perhaps an even more important challenge is the coordination of projects. The design of the electronic curriculum for online projects should take into consideration the reality of the LMIC to be included. Additionally, the impact of eLearning activities alone, without the combination of visits/missions and fellowship models, may weaken the connection between educators and trainees and lead to lack of engagement in courses and attrition. ${ }^{25,34,35}$

\section{Long-Term Long-Distance Mentorship}

This model of international neurosurgical training is a common practice between physicians. It is not uncommon that after a fellowship a long-term relationship between trainee and mentor will take place.

In the same way, this long-distance mentorship usually arises within initiatives for international education in neurosurgery in LMICs. In the last 10 years, through multiple missions and fellowship training programs, strong mentor-mentee relationships have been achieved with neurosurgeons in several LMICs. This model requires a strong commitment from both sides and it helps to achieve sustainability of the initiatives included in previously described models. Additionally, this model allows evaluation of long-term outcomes of educational initiatives and may be useful for the development of further international initiatives. On the other hand, the implementation of this model is challenging. The scarce availability of funding for long-term partnerships may limit the productivity of such collaborations. ${ }^{2}$

\section{Discussion}

\section{Difficulties and Limitations of the Different Models}

The development of international surgical collaborations faces challenges in HICs and LMICs. These challenges may be classified as individual, community, and system barriers. ${ }^{10}$ Individual barriers include questions such as loss of income, family commitments, skepticism about global surgery, lack of sufficient professional experience, and concerns for physical and emotional well-being. 
Community barriers include insufficient mentorship and lack of knowledge about global surgery and lack of support from colleagues. Finally, system challenges include major limitations such as minimal time available, poor academic recognition, and lack of funding. ${ }^{10}$ Most of the individual limitations may be minimized by educating surgeons about global surgery and its impact, and developing programs according to different time availability. Systemic barriers require more profound changes, however, including the development of an academic track in global surgery, with time specifically available for those activities, and an increased number of grants for global surgery projects.

When defining strategies, it should be considered that the ultimate goal of those projects should be centered on patient care and bilateral exchange of knowledge, with support given to the development of an independent, sustainable practice in the host country/region. Therefore, when organizing missions, one should avoid well-described ethical conflicts, ${ }^{16,20}$ the "white knight syndrome," and providing care below a minimal standard or using either suboptimal or expensive/nonavailable equipment. In the first scenario, the visiting surgeon can perform some surgical procedures without a significant transfer of knowledge, decreasing the probability of long-term local sustainability. In general, these situations usually lead to futility of the mission, as the host surgeons do not benefit from a learning experience and have to manage complications derived from the surgical procedures. ${ }^{17}$ The visiting surgical team should also be able to adapt and incorporate new abilities in a setting with limited technology and surgical equipment. Ideally, the transfer of knowledge should not be restricted to neurosurgical care, but should also include anesthesia as well as allied health professions such as nursing and physical therapy, to improve the care of patients.

Interestingly, the literature is scarce concerning the opinion of surgeons from LMICs about surgical missions. Ginwalla and Rickard report their perspectives as surgeons working in Rwanda about the impact of such missions in that region. ${ }^{13}$ In this paper, the authors report on potential drawbacks of surgical missions that need to be addressed, including poor patient selection, consumption of resources and operating room availability, and inappropriate selection of educational activities. There are also concerns about cost-effectiveness and long-term impact. ${ }^{7,33}$ Current results, however, suggest a positive impact of such collaborations. A recent meta-analysis demonstrated that many surgical interventions, including surgical treatment of hydrocephalus ( $\$ 108.74$ per disability-adjusted life year), are, in fact, cost-effective in resource-poor countries. ${ }^{7}$ Neurosurgery in general is an expensive specialty and that needs to be taken into consideration. The total cost of neurosurgical procedures in LMICs may vary from $\$ 291 \pm \$ 101$ for burr hole evacuations to $\$ 1221 \pm \$ 473$ for excision of brain tumors. ${ }^{1}$

The long-term impact of such missions still requires further study. In fact, there is a need for instruments for evaluation of international collaborations. ${ }^{21}$ It is clear, though, that there is a need for collaborations beyond short-term surgical missions, with support of improvement of facilities and training of other healthcare person- nel, which should be supported by the different organizations involved in international collaborations. ${ }^{7,11,12,15}$

Cultural differences impact the development of international collaborations. Surgeons from HICs, with the role of educators, should be respectful toward the local traditions of LMICs and understand that some of the usual methods applied at home will not be useful or available in the visited country. Language, working hours, caseload, and doctor-patient relationships may be significantly different and those factors should be taken into consideration when trying to disseminate a new technique/methodology in a specific location. ${ }^{13,37}$ Mutual respect between surgeons is mandatory and one should avoid a position of superiority; it is important to understand that surgeons from LMICs may actually have better surgical strategies and skills when operating in a limited-resource setting. Therefore, it is not surprising that visiting surgeons may at times learn more than host surgeons on some occasions.

Ethical challenges are present in international collaborations..$^{2,16,18}$ In surgical missions, ethical issues may be classified as venue-related or visitor-related. ${ }^{16}$ The selection of the location for the project, the selection of patients and informed consent, the expectations about the surgeries to be performed, and the misapplications of teachings are included as venue-related issues. Common visitor-related issues include coping with performing "second-best" treatments in the visiting country, and conflict of interest/ personal gains. One should have the clear objective of helping patients and disseminating surgical techniques when volunteering for such activities. The same ethical concepts applied in HICs, such as non-malfeasance, truth-telling, and patient confidentiality, should be applied in LMICs. Engagement in political aspects of the visited region may impact the development of the project and is usually not encouraged. The support of the medical industry is usually necessary, and the organizing committee should be aware of potential conflicts of interest, not only during the surgical mission but also when returning home. Another challenge is the limited funding available for global surgery projects. Governmental support is usually not available and most resources available are a result of donations, which limits the routine development of projects. Often, involved surgeons directly pay the costs of the projects, which will negatively impact the production of long-term collaborations. The lack of tools to assess the impact of global surgery initiatives limits the assessment of outcomes of those projects and makes it hard to justify the application of resources for such initiatives. Adequate evaluation of the impact of global surgery projects may improve the allocation of funds for those initiatives.

The fellowship training model has been associated with the risk of "brain drain" from LMICs to HICs. To understand the dynamics of the "brain drain phenomenon," it is necessary to consider the role of destination countries (usually HICs), source country (LMICs), and individual physicians in this problem. ${ }^{23}$ Destination countries usually do not actively support migration, i.e., no active recruitment of doctors from LMICs to HICs. However, passive recruitment is not rare. The abundant resources, better quality of life and work, and political stability in those countries usually attract doctors from less-favored re- 
gions. Source countries, in turn, usually face significant economic and political problems and have a much higher demand for physicians. Migration due to those reasons is not uncommon and affects not just health professionals. However, doctors are an important and expensive "good" in those countries. Emigration of healthcare workers from sub-Saharan Africa costs the region approximately \$2.17 billion (US dollars). ${ }^{28}$ Improvement in the health system of those regions, including not only better infrastructure but also academic opportunities, could minimize the migration of specialized physicians. A recent study in the sub-Saharan region concluded that the surgical graduates undertaking local training are usually retained in their country of origin and that the investment in local surgical training programs could have helped to increase retention rates. ${ }^{19}$ This suggests that the problem might be more related to training in an $\mathrm{HIC}$ at a residency level than at a fellowship level. International collaborations, with continuing education programs and multiinstitutional research activities, could help to establish academic programs in LMICs and potentially reduce this phenomenon. ${ }^{14}$

Ideally, long-term collaborations should serve as the foundation to achieve improvement not only in neurosurgery but also in anesthesia, critical care, rehabilitation, and oncology. ${ }^{32,36}$ The NED Foundation conducted multiple missions over the last decade that have led to a long-term educational collaboration, focused not only on neurosurgical care but also on neurosurgery-related disciplines. Among other initiatives, they have developed an intensive care unit for critical patient care that allows the local hospital to increase the complexity of neurosurgical cases. ${ }^{36}$ Another example is the collaboration between Duke University and New Mulago Hospital in Uganda, where not only academic but also infrastructure improvement has occurred as a result of this partnership. ${ }^{15}$

The possibilities of long-distance education via the Internet offer opportunities for continued education, especially during the periods between missions. This can be useful for continued education and monitoring the impact of surgical missions. Nevertheless, in order to plan a successful online curriculum, the organizers need to be aware of the cultural differences. Although differences in ethical, moral, and religious perspectives between mentors and trainees are common in all models of international education, these may be more significant in a model with a limited interaction, such as the online platform. ${ }^{4}$ Furthermore, online education alone is considered a suboptimal model because it allows only limited interaction between participants. ${ }^{25}$

\section{Defining Goals and Assessing Results: How to Study the Impact of International Collaborations?}

The literature on international collaborations consists mostly of opinion ${ }^{17}$ or single-center observational studies ${ }^{6}$ and philosophical work, ${ }^{16}$ with little analysis of relevant quality indicators or outcome measures. ${ }^{21}$ In fact, there is a need for development of tools for assessment of the impact of such projects, which could demonstrate the real importance of some projects and facilitate the selection and allocation of funds for specific projects in this field. Strategies for monitoring and evaluation of global neuro- surgery may assist in the development of new strategies for improvement of global neurosurgery.

Inspired by previous strategies for projects on communicable diseases, the Framework for the Assessment of International Surgical Success (FAIRNeSS) was proposed in $2015{ }^{21}$ The input-process-output-outcome-impact framework was used to organize indicators of successful surgical programs into the FAIRNeSS criteria. Inputs refer to equipment, finances, and time invested to achieve outputs, such as better-trained surgeons. The outputs result in processes, such as ongoing staff training. The outputs, if successful, may lead to outcomes with a measureable impact, such as lower morbidity and mortality of surgical interventions in LMICs. ${ }^{21}$ Achievement of long-term indicators of success is an important indicator of the program success. Generally, inputs, outputs, and outcomes should be measured continuously, once a year, and every $2-5$ years, respectively. As the FAIRNeSS criteria are an evolving tool, the authors believe that future studies including the perspective of politicians and hospital administrators may add significant contributions and refine these criteria.

\section{Developing the Next Generation: How to Attract More Surgeons and Centers}

Global neurosurgery is a relatively new field, with no track for academic promotions, and is associated with lack of funding and no reimbursement. There is a need to attract young surgeons into the field, but this is a significant challenge. The limited availability of time in the early years of a neurosurgical career, the need for growth in academic realms, and financial support limitations impact the attraction of surgeons.

Different strategies can be implemented to minimize such challenges. A promotional track on global surgery could lead to the development of time specifically devoted to those activities, organizational support, and financial incentives. Involvement of trainees from HICs in global surgery may positively impact their surgical training and also foster the interest of more young participants. Accumulation of data demonstrating the successful impact of international projects may support the establishment of chairs in global surgery, the development of funds, and allocation of resources for growth of the field. ${ }^{10}$

The attraction of centers in LMICs also needs to be improved. The selection of centers with the potential to become "centers of excellence" in global surgery in LMICs should be encouraged. Those centers would maintain collaborations with HIC institutions while being responsible for disseminating knowledge and developing collaborations in their region. However, all interested locations may play a role in global surgery if projects are adequately designed.

\section{Conclusions}

The inequality of access to surgical care is a global problem. International collaborations between HICs and LMICs are an important step in the development of surgical education and patient care in parts of the world with scarce access to surgical treatment. The scarce availability of funds, lack of organizational agencies, and poor academ- 
ic recognition are major issues that need to be addressed for the improvement of global neurosurgery educational initiatives. Finally, it is paramount to develop and validate methods for evaluation of international collaborations that can be used to demonstrate the real impact of those projects.

\section{References}

1. Abdelgadir J, Tran T, Muhindo A, Obiga D, Mukasa J, Ssenyonjo $\mathrm{H}$, et al: Estimating the cost of neurosurgical procedures in a low-income setting: an observational economic analysis. World Neurosurg 101:651-657, 2017

2. Ahmad MU, Ford PJ: Ethical obligations in attempting to do good in a surgical mission: reflections on the neurosurgical mission to Mongolia. World Neurosurg 101:748-749, 2017

3. Bagan M: The Foundation for International Education in Neurological Surgery. World Neurosurg 73:289, 2010

4. Blankstein U, Dakurah T, Bagan M, Hodaie M: Structured online neurosurgical education as a novel method of education delivery in the developing world. World Neurosurg 76:224-230, 2011

5. Cadotte DW, Sedney C, Djimbaye H, Bernstein M: A qualitative assessment of the benefits and challenges of international neurosurgical teaching collaboration in Ethiopia. World Neurosurg 82:980-986, 2014

6. Cadotte DW, Viswanathan A, Cadotte A, Bernstein M, Munie T, Freidberg SR: The consequence of delayed neurosurgical care at Tikur Anbessa Hospital, Addis Ababa, Ethiopia. World Neurosurg 73:270-275, 2010

7. Chao TE, Sharma K, Mandigo M, Hagander L, Resch SC, Weiser TG, et al: Cost-effectiveness of surgery and its policy implications for global health: a systematic review and analysis. Lancet Glob Health 2:e334-e345, 2014

8. Corley JA, Haglund M: How neurosurgery fits into the Global Surgery 2030 agenda. Neurosurgery 79:E544-E545, 2016 (Letter)

9. Dewan MC, Rattani A, Fieggen G, Arraez MA, Servadei F, Boop FA, et al: Global neurosurgery: the current capacity and deficit in the provision of essential neurosurgical care. J Neurosurg [epub ahead of print April 27, 2018; DOI: 10.3171/2017.11.JNS171500]

10. Fallah PN, Bernstein M: Barriers to participation in global surgery academic collaborations, and possible solutions: a qualitative study. J Neurosurg [epub ahead of print April 6, 2018; DOI: 10.3171/2017.10.JNS17435]

11. Freed J, Medoff S: Communication: improving the view from this side. JAMA Surg 150:1100, 2015

12. Fuller A, Tran T, Muhumuza M, Haglund MM: Building neurosurgical capacity in low and middle income countries. eNeurologicalSci 3:1-6, 2015

13. Ginwalla R, Rickard J: Surgical missions: the view from the other side. JAMA Surg 150:289-290, 2015

14. Hagander LE, Hughes CD, Nash K, Ganjawalla K, Linden A, Martins Y, et al: Surgeon migration between developing countries and the United States: train, retain, and gain from brain drain. World J Surg 37:14-23, 2013

15. Haglund MM, Kiryabwire J, Parker S, Zomorodi A, MacLeod D, Schroeder R, et al: Surgical capacity building in Uganda through twinning, technology, and training camps. World J Surg 35:1175-1182, 2011

16. Howe KL, Malomo AO, Bernstein MA: Ethical challenges in international surgical education, for visitors and hosts. World Neurosurg 80:751-758, 2013

17. Howe KL, Zhou G, July J, Totimeh T, Dakurah T, Malomo $\mathrm{AO}$, et al: Teaching and sustainably implementing awake craniotomy in resource-poor settings. World Neurosurg 80:e171-e174, 2013

18. Hughes SA, Jandial R: Ethical considerations in targeted paediatric neurosurgery missions. J Med Ethics 39:51-54, 2013
19. Hutch A, Bekele A, O’Flynn E, Ndonga A, Tierney S, Fualal $\mathrm{J}$, et al: The brain drain myth: retention of specialist surgical graduates in east, central and southern Africa, 1974-2013. World J Surg 41:3046-3053, 2017

20. Ibrahim GM, Bernstein M: Models of neurosurgery international aid and their potential ethical pitfalls. Virtual Mentor 17:49-55, 2015

21. Ibrahim GM, Cadotte DW, Bernstein M: A framework for the monitoring and evaluation of international surgical initiatives in low- and middle-income countries. PLoS One 10:e0120368, 2015

22. Karabatsou K: Neurosurgery fellowships in Canada: expectations and practical considerations. Br J Neurosurg 24:224226, 2010

23. Karan A, DeUgarte D, Barry M: Medical "brain drain" and health care worker shortages: how should international training programs respond? AMA J Ethics 18:665-675, 2016

24. Kinasha A, Kucia EJ, Vargas J, Kavolus J, Magarik J, Ellegala DB, et al: Neurosurgery in Tanzania: a discussion of culture, socioeconomics, and humanitarians. World Neurosurg 78:31-34, 2012

25. Liang KE, Bernstein I, Kato Y, Kawase T, Hodaie M: Enhancing neurosurgical education in low- and middle-income countries: current methods and new advances. Neurol Med Chir (Tokyo) 56:709-715, 2016

26. Meara JG, Greenberg SL: The Lancet Commission on Global Surgery Global surgery 2030: evidence and solutions for achieving health, welfare and economic development. Surgery 157:834-835, 2015

27. Meara JG, Leather AJ, Hagander L, Alkire BC, Alonso N, Ameh EA, et al: Global Surgery 2030: evidence and solutions for achieving health, welfare, and economic development. Surgery 158:3-6, 2015

28. Mills EJ, Kanters S, Hagopian A, Bansback N, Nachega J, Alberton $\mathrm{M}$, et al: The financial cost of doctors emigrating from sub-Saharan Africa: human capital analysis. BMJ 343:d7031, 2011

29. Park KB, Johnson WD, Dempsey RJ: Global neurosurgery: the unmet need. World Neurosurg 88:32-35, 2016

30. Piquer J, Qureshi MM, Young PH, Dempsey RJ: Neurosurgery Education and Development program to treat hydrocephalus and to develop neurosurgery in Africa using mobile neuroendoscopic training. J Neurosurg Pediatr 15:552-559, 2015

31. Punchak M, Mukhopadhyay S, Sachdev S, Hung YC, Peeters S, Rattani A, et al: Neurosurgical care: availability and access in low-income and middle-income countries. World Neurosurg 112:e240-e254, 2018

32. Romach MK, Rutka JT: Building healthcare capacity in pediatric neurosurgery and psychiatry in a post-Soviet system: Ukraine. World Neurosurg 111:166-174, 2018

33. Saxton AT, Poenaru D, Ozgediz D, Ameh EA, Farmer D, Smith ER, et al: Economic analysis of children's surgical care in low- and middle-income countries: a systematic review and analysis. PLoS One 11:e0165480, 2016

34. Sedney CL, Siu J, Rosseau G, Dempsey R, Bernstein M: International neurosurgical volunteerism: a temporal, geographic, and thematic analysis of foundation for international education in neurological surgery volunteer reports. World Neurosurg 82:963-968, 2014

35. Shrime MG, Bickler SW, Alkire BC, Mock C: Global burden of surgical disease: an estimation from the provider perspective. Lancet Glob Health 3 (Suppl 2):S8-S9, 2015

36. Spanu F, Piquer J, Panciani PP, Qureshi MM: Practical challenges and perspectives for the development of neurosurgery in a peripheral East African hospital during a one-volunteer midterm mission. World Neurosurg 111:326-334, 2018

37. Vander Burg R, Kabetu C, Ayala R: Surgical missions: a view from yet another side. JAMA Surg 150:688, 2015 
38. Weiser TG, Regenbogen SE, Thompson KD, Haynes AB, Lipsitz SR, Berry WR, et al: An estimation of the global volume of surgery: a modelling strategy based on available data. Lancet 372:139-144, 2008

\section{Disclosures}

Dr. Hodaie is a founder of the NEURONproject (Neurosurgical Education with Universal Reach Online), a nonprofit organization.

\section{Author Contributions}

Conception and design: Almeida, Velásquez, Marigil, Bernstein. Acquisition of data: Almeida, Velásquez, Karekezi, Marigil.
Analysis and interpretation of data: Almeida, Hodaie. Drafting the article: Almeida, Velásquez, Marigil, Bernstein. Critically revising the article: Karekezi, Marigil, Hodaie, Rutka, Bernstein. Reviewed submitted version of manuscript: Hodaie, Rutka, Bernstein. Approved the final version of the manuscript on behalf of all authors: Almeida.

\section{Correspondence}

Joao Paulo Almeida: Toronto Western Hospital, University Health Network, University of Toronto, ON, Canada.jpaulocavalcante@ yahoo.com.br. 